\title{
Hands-on approach to groundwater system investigation: suggestions for new use of existing characterization tools
}

\section{Un approccio applicativo nelle indagini su sistemi idrogeologici: suggerimenti per un nuovo uso di esistenti strumenti di caratterizzazione}

Paolo Cerutti - IDRICOM Consortium - Via Tirotti 11, 29122 Piacenza, Italy - paolo.cerutti@ecotercpa.it

Massimo Sacchetto - Freelance Consultant - maxsacchetto@gmail.com

Keywords: drilling, hydrogeological setting, site characterization, groundwater technologies

Parole chiave: perforazione, contesto idrogeologico, caratterizzazione del sito, tecnologie per le acque sotterranee

\section{Introduction}

In hydrogeology there is a clear distinction between some theoretical and practical aspects. The former include for example those related to hydrogeological studies, modeling of aquifers, evaluation of the water-bearing potential of a site, assessment of the impact of the exploitation of groundwater; the latter include measuring hydraulic parameters such as hydraulic conductivity and transmissivity, the design of wells, the choice of the most suitable technique for drilling and constructing wells of different types, or the most appropriate technology for monitoring and testing in situ, etc. Sometimes the practical, purely geognostic aspect, i.e. direct in-situ knowledge obtained through in-situ tests and/or coring, is neglected or overshadowed, although of great importance in all contexts of hydrogeological interest.

\section{Scope}

With the aim of stimulating discussion and providing specialists with food for thought, this paper presents some examples of both advanced geognostic drilling techniques, i.e. aimed at gathering knowledge of the groundwater system rather than mere drilling for the installation of wells, and of instrumentation and techniques relating to the implementation of direct in-situ testing and sampling of both soil/rock and of groundwater, which we consider particularly useful for the characterization and parameterization of the hydrogeological setting of interest. These include: wireline drilling systems, measurement while drilling (MWD), tools for characterizing both aquifers (in-situ permeability tests) and aquitards (borehole penetrometer tests and permeability tests), and sampling techniques and technologies.

\section{Background}

Generally speaking, for investigating the subsoil, QUALITATIVE analysis (such as geophysics and coring drilling) and QUANTITATIVE analysis (such as in situ tests, laboratory tests on samples) are performed (Lunne 2001). Any parameter of the soil can be measured and/or estimated by using a certain method/tool with a certain degree of reliability, according i.e. to data in table 1 (Lunne 2001) compiled for tests which are widely used in offshore geotechnical drilling. Hydrogeological drilling is commonly "no coring", the stratig- raphy already being known from cuttings analysis and from "manual" monitoring of drilling parameters. This can often lead to mistakes being made, given that the stratigraphic log is highly dependent on human factors. Continuous coring (hence withdrawal of cores and samples) is the solution for perfect stratigraphic logging, but in the majority of cases the drilling tools used for water-well drilling are not suitable for continuous coring, especially at great depth. Common tools which are widely used for shallow (up to $30-40 \mathrm{~m}$ ) geotechnical investigations (core-barrels and testing tools driven by rods and casing the hole) do not constitute a solution, because the greater the depth the slower the operations. Therefore it is highly recommended that WIRELINE tools (core-barrels and testing tools) be used for hydrogeological purposes for depths greater than $30-40 \mathrm{~m}$.

\section{Coring, sampling, testing with wireline and standard method}

As an alternative to no-coring drilling (direct circulation with roller bit, chisel, rotary-percussion drilling), coring drilling, either continuous or discontinuous, should be considered for the collection of cores or samples. The distinction between a CORE and a SAMPLE is very fine: CORES are retrieved from "CORE-BARRELS" (simple, double, triple wall depending on the number of walls interposed between the external surface of the core and the hole) and extruded when brought to the surface, while SAMPLES are usually contained in thin wall tubes (stainless steel or PVC) and not extruded before laboratory tests are carried out. Pieces of core (or some cuttings) are also sometimes considered samples. Undisturbed samples are those withdrawn from soft cohesive soils (compression strength lower than $150 \mathrm{kPa}$ ); it is not practically possible to obtain undisturbed samples in sands without using highly specialised and extremely expensive methods (AGI 1977).

\section{Standard method}

the coring is carried out using a simple or double core-barrel driven by rods; this means that for coring e.g. from 120 to $123 \mathrm{~m}$ with a $3 \mathrm{~m}$ long core-barrel, $2 \times 120+3 \mathrm{~m}$ of rods have to be screwed and unscrewed in order to drive the $3 \mathrm{~m}$ corebarrel into the soil and retrieve it. Then (after the core-barrel has been retrieved) the casing has to be driven down to -123 


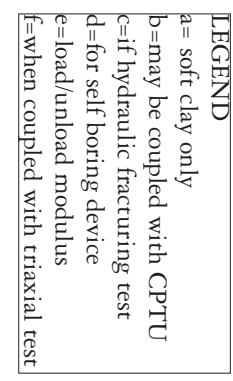

\begin{tabular}{|c|c|c|c|c|c|c|c|c|c|}
\hline 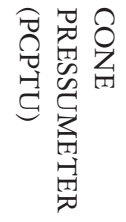 & 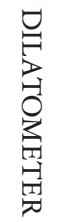 & 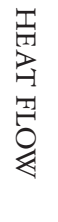 & 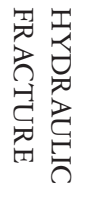 & 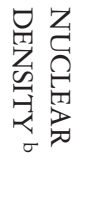 & 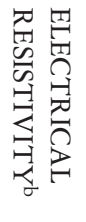 & 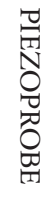 & $\begin{array}{l}7 \\
0 \\
0\end{array}$ & & 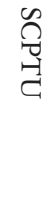 \\
\hline
\end{tabular}

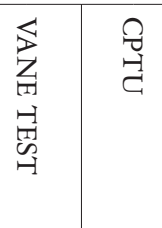

○ิ

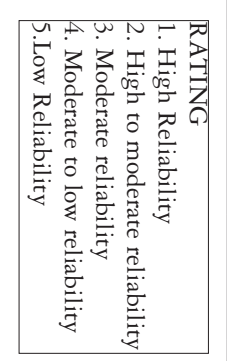

永

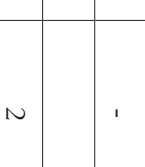

\section{1}

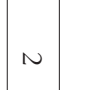

$-$

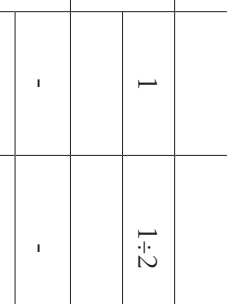

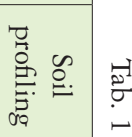

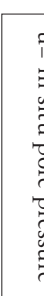

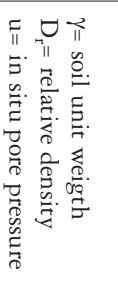

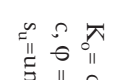

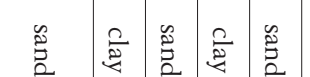

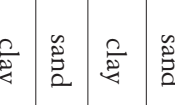

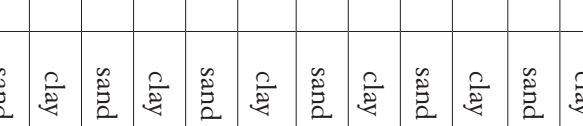

i.

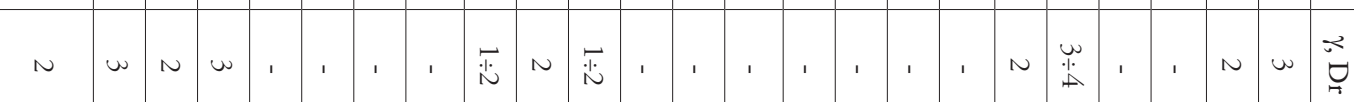

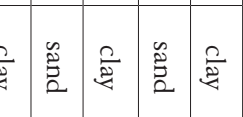

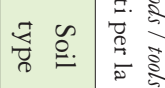

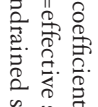

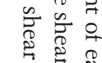

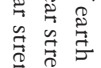

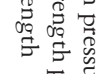

焉

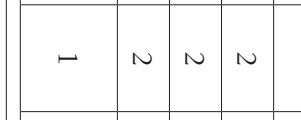

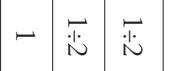

\begin{tabular}{|l|l|l|l|l|l|l|l|l|l|}
1 & 1 & 1 & - & $N$ & 1 & 1 & - & $N$ & $=$ \\
$w$ & 1 &, & $A$ & $\omega$ &, & $N$ & $N$ & $w$ & $\varrho$
\end{tabular}

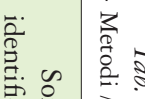

苍.

节主

5
0.5
0

है. है

2.

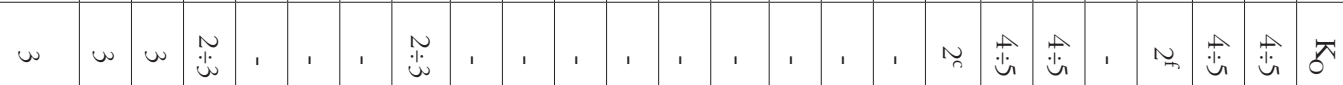

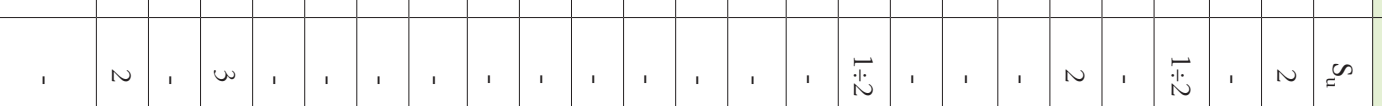

$\sum_{2}$

至

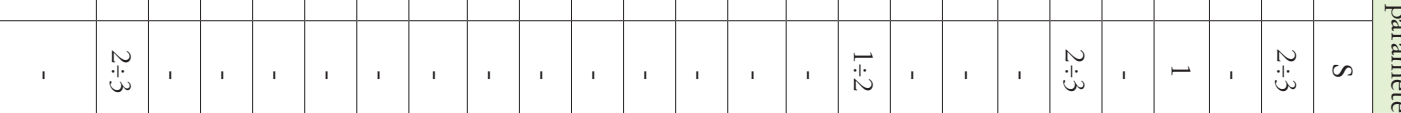

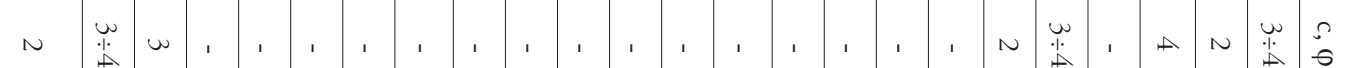
莫

is $<0$ 定

II 3 ,

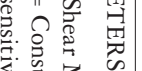

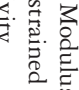

हू

$\begin{array}{ccc}0 & \pi \\ 0 & \pi & 0 \\ 0 & 0 & 0 \\ 0 & 0 & 0\end{array}$

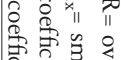

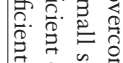

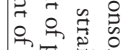

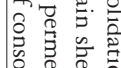

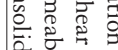

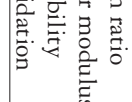

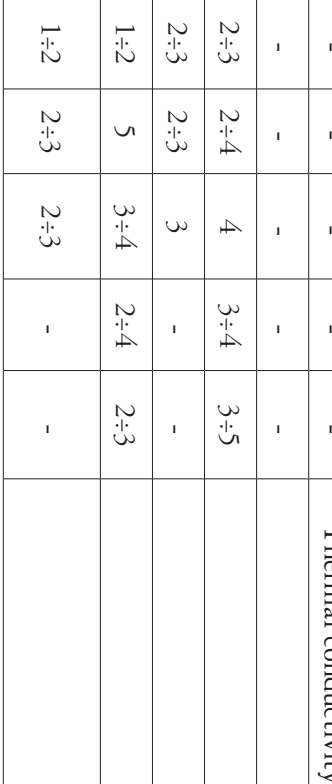

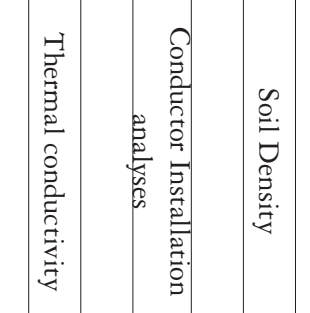

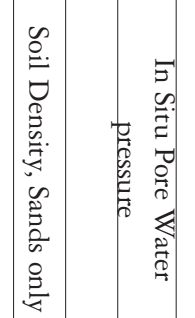

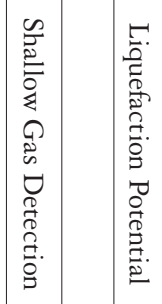

点.


to avoid swelling and collapsing of the borehole (Fig. 1) The quality of the core is often low, as is the recovery ratio, especially in non-cohesive soils (sands). Down-the-hole testing is always carried out using rods and casing whenever possible.

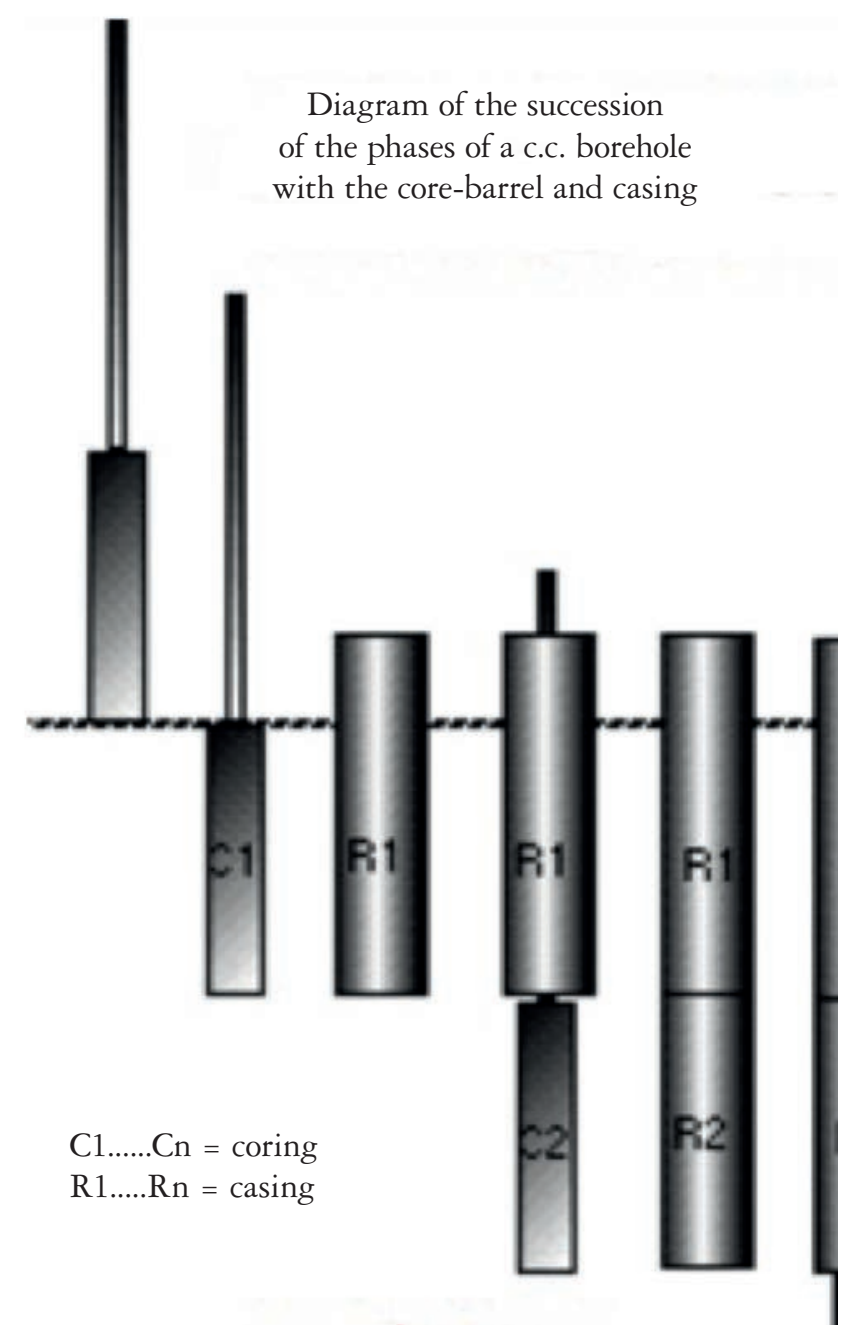

Fig. 1: Standard method of coring using rods for driving the core-barrel, then casing the bole

Fig. 1: Metodo standard di carotaggio aste-carotiere con rivestimento del foro

\section{Wireline:}

Initially used for rock continuous core drilling, it was later modified for boring in soils of any type; it is widely used in oil-drilling and OFFSHORE drilling (Lunne, 2001). Inside the rods (usual diameter range $\varnothing 60 \div 160 \mathrm{~mm}$ ) there is a CORE-BARREL which latches inside the drill-string. The lower part of the drill-string is shaped like the external part of a double core-barrel, while the corresponding internal part of a double/triple core-barrel is lowered and retrieved by a wire (hence the name "wireline") and latching is ensured by one or more clamps. The retrieval of the inner core-barrel is achieved using an "overshot" which latches and unlatches a clamp mechanism (Sacchetto, 2004; ASTM D5876-95, 2012) (Fig. 2, Fig. 3). Theoretically almost any down-the-hole opera- tion can be carried out with a wireline device. The great advantage of wireline is that the time required for drilling does not depend on depth, as it does with rods (standard method); moreover the wireline system, if properly used, allows a much higher recovery ratio and much higher quality of cores (given that the drill-bit of the inner barrel can easily and quickly be changed any time the type of soil requires it). Down-the-hole testing is carried out with wireline tools (therefore lowered and retrieved by the same wire managing the core-barrels); sometimes down-hole electronic devices are equipped with a microcomputer and memory since it is not always possible to convey data to the surface. It is also possible to drill without coring, using a wireline roller bit or chisel, as well as wireline SAMPLING, using adapted (customized) versions of samplers driven by rods. In large diameter water-well deep drilling (direct circulation, with rods) it would be possible to combine wireline and coring, sampling, and testing with nocoring standard tools, making it possible to switch very easily from no-coring to coring or testing without changing rods and equipment. The wireline system is well standardized in ASTM D5876-95 (reapproved 2012).

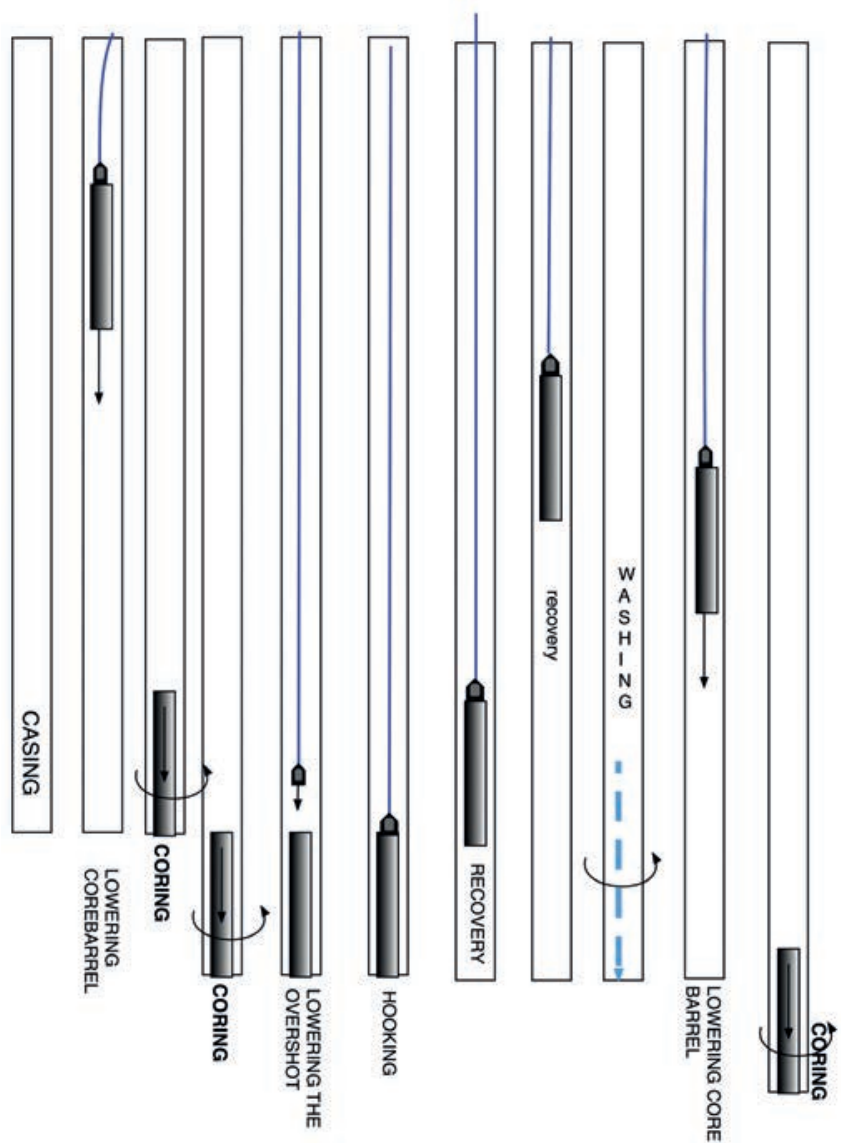

Fig. 2: Typical pattern of wireline coring.

Fig. 2: Tipica sequenza in un carotaggio wireline. 


\section{New developments}

\section{Monitoring While Drilling (MWD)}

This derives from methods which have been used for years in the oil-drilling sector. It is defined in several ways, according to the manufacturing company concerned, and is commonly known in English as MWD (monitor while drilling) (Burgoyne, Young 1974; Borgia et al. 1990; Sacchetto, Melander et al. 2001).

Some pressure sensors, depth transducers or volume transducers are applied to a hydraulic drill rig; the signals of the sensors are amplified, modified and digitalized and recorded using a suitable device, and sometimes printed in real time during the drilling (usually no-coring drilling) (Hamelin J.P. et al. 1983).

The magnitudes measured can be all those in play during drilling, which commonly are:

- $\quad$ push pressure;

- $\quad$ torque pressure;

- drilling fluid pressure;

- RPM;

- $\quad$ speed of drilling;

- $\quad$ volume of the drilling fluid.

With proper calibration, and for a certain drill rig and for a certain drilling tool, it is possible to calibrate the abovementioned pressure in order to obtain the direct values, for example push $(\mathrm{N})$ instead of push pressure, torque $(\mathrm{Nm})$ instead of torque pressure, etc.

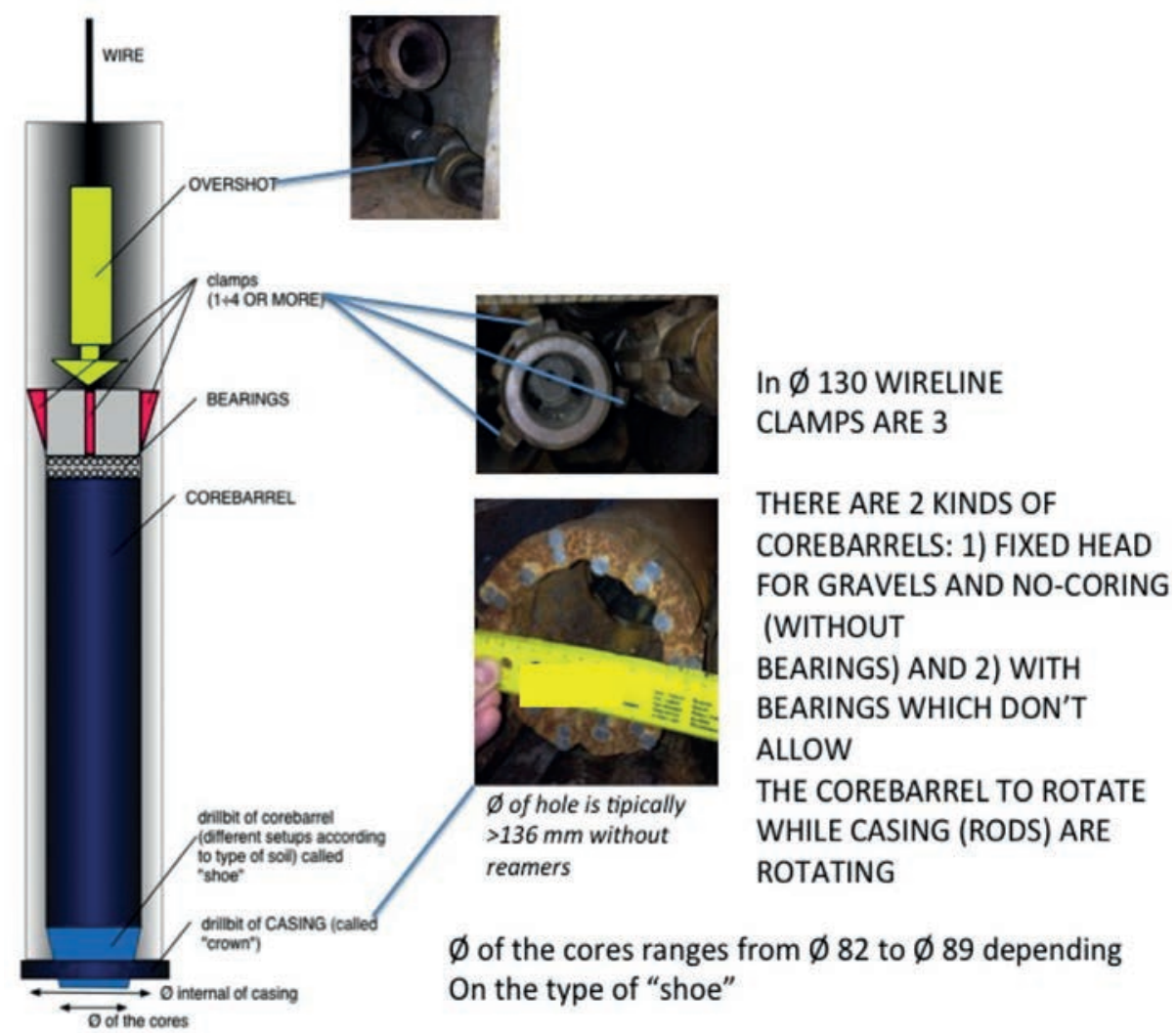

Generally MWD is used in no-coring drilling and the combined recording of the drilling parameters together with the "cutting" examination allows a good definition of the stratigraphy (Borgia et al. 1990).

From a quantitative point of view, some experts correlate geotechnical parameters to characteristic magnitudes or to their combination. In the majority of cases, the obtaining of geotechnical parameters from MWD depends on an analysis of the energy used in boring with that tool by calculating the SPECIFIC ENERGY (Bru et al. 1983; Borgia et al. 1990) (Fig. 4). In any case, in hydrogeological drilling practices the use of MWD can reliably provide:

- together with cutting analysis: STRATIGRAPHIC LOG;

- $\quad$ very accurate (2 $\mathrm{cm}$ accuracy) definition of thickness of layers;

- accurate definition of aquifers and aquitards;

- together with calculation of specific energy: GEOMECHANICAL PARAMETERS;

- together with other tests: POTENTIAL YIELD OF ACQUIFERS and ASSESSMENT OF VULNERABILITY OF AQUITARDS. 


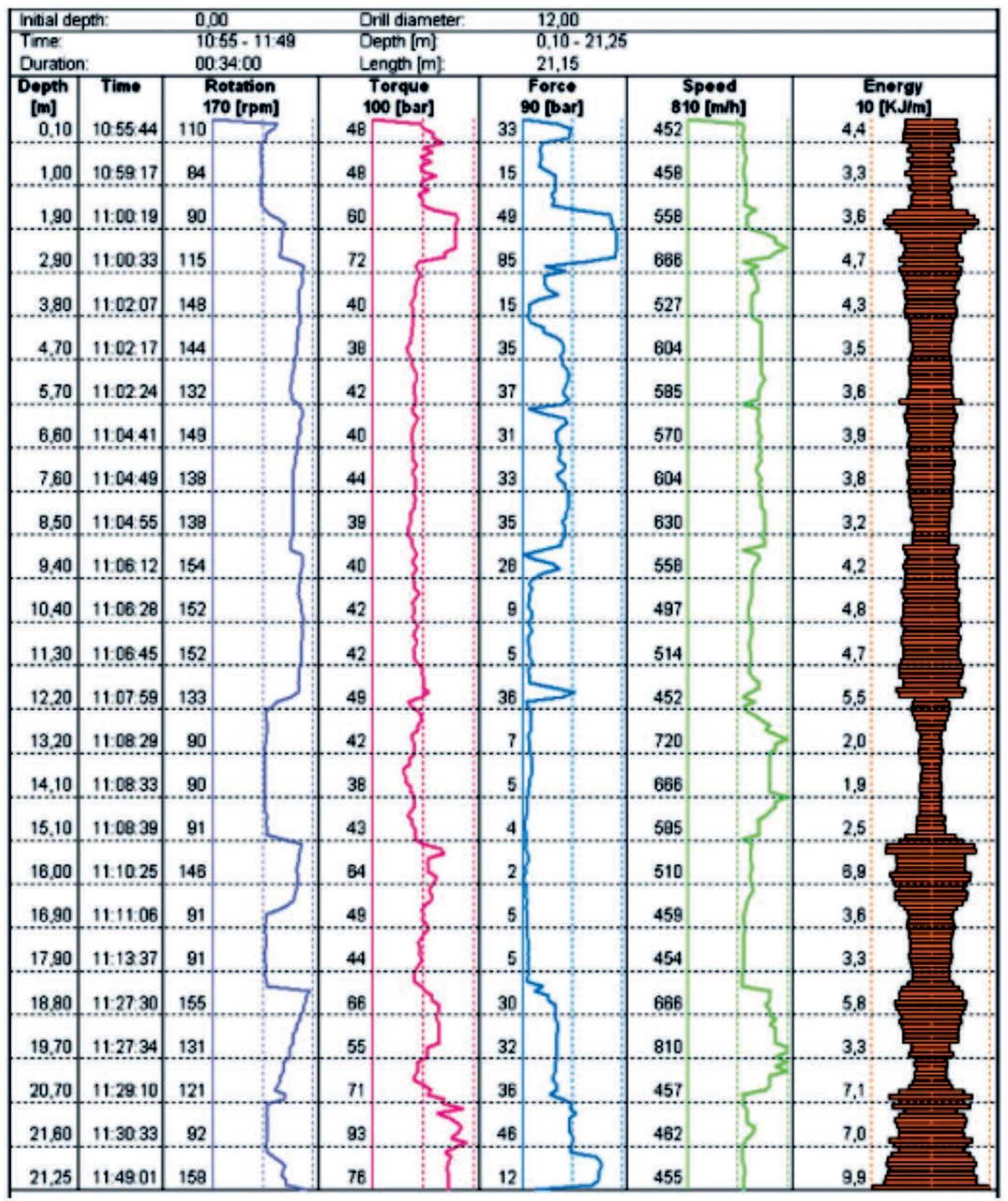

Fig. 4: Example of MWD (data Monitoring While Drilling) diagraphy with evaluation of specific energy.

Fig. 4: Esempio di diagrafia MWD (lettura dati in corso di perforazione) con stima di energia specifica. 


\section{Down-Hole wireline equipment (new developments) for hydrogeological investigation \\ Permeameter and Fluid Sampler}

Comprises a tube containing an under-vacuum vial connected to a filter; the bottom of the tube has an auger which penetrates the uncontaminated soil at the bottom of the hole; once the auger has penetrated one meter the drill-string is pulled up and the filter is mechanically opened, so the vial starts to fill. A pressostat on the top of the vial measures the variation in pressure versus time, so as to obtain a permeability coefficient (Sacchetto et al. 2012) (Fig. 5, Fig. 6).

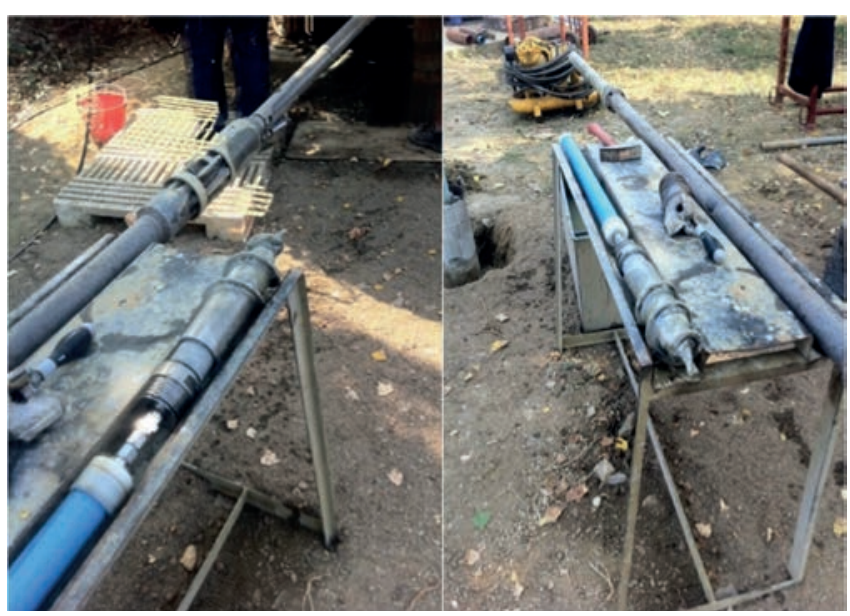

Fig. 5: Wireline permeameter.

Fig. 5: Permeametro wireline.

\section{Wireline down-the-hole water well (filter)}

This is a wireline "down-the-hole water well" to be installed in a pre-hole, using the casing as the non-filtering part of a small water well; it allows pumping and permeability tests while advancing the wireline casing (without installing a water well each time a pumping test is required) (Sacchetto et al. 2012) (Fig. 7)

\section{CPTWD®}

"CPTWD" stands for Cone Penetration Test While Drilling (Fig. 8); it can be considered as an integration between a standard CPTU, a wireline coring system, and in suitable rigs the MWD (monitoring while drilling) (Cestari 1999; Sacchetto et al. 2004) (Fig. 9). The CPTWD allows alternation between CPTU strokes and drilling, sampling, coring, downthe-hole testing (i.e. SPT or Lefranc or Vane Test, etc), and it is possible to install geotechnical instrumentation (diameter of the hole $\geq 130 \mathrm{~mm}$ ) when the drilling is completed. In hydrogeology it can be used efficiently (in penetrable soils) for determining the permeability behavior of aquitards, together with a wide range of geotechnical parameters given by CPTU piezocone testing at much greater depths than standard CPTU run with a static penetrometer, and allows execution of CPTU tests in alternating types of soils (e.g. alternating gravel/cobbles and clay/sand) by simply swapping the CPTU with a core-barrel/roller bit (defined also as "casing advancer") (Cestari 1999; Lunne 2001; Mayne 2007).

Fig. 6: Wireline permeameter (bow it works).

Fig. 6: Permeametro wireline (come funziona).
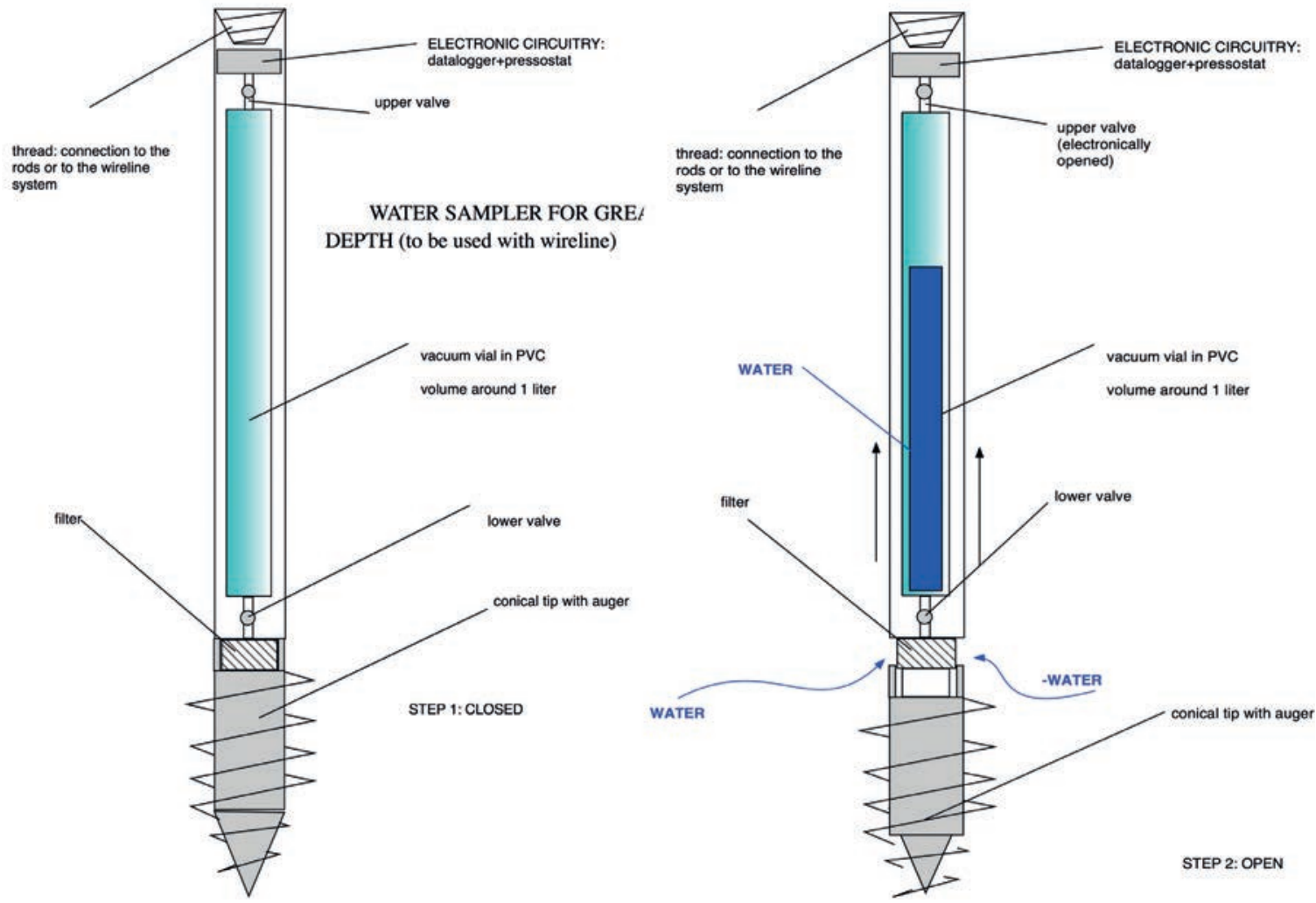

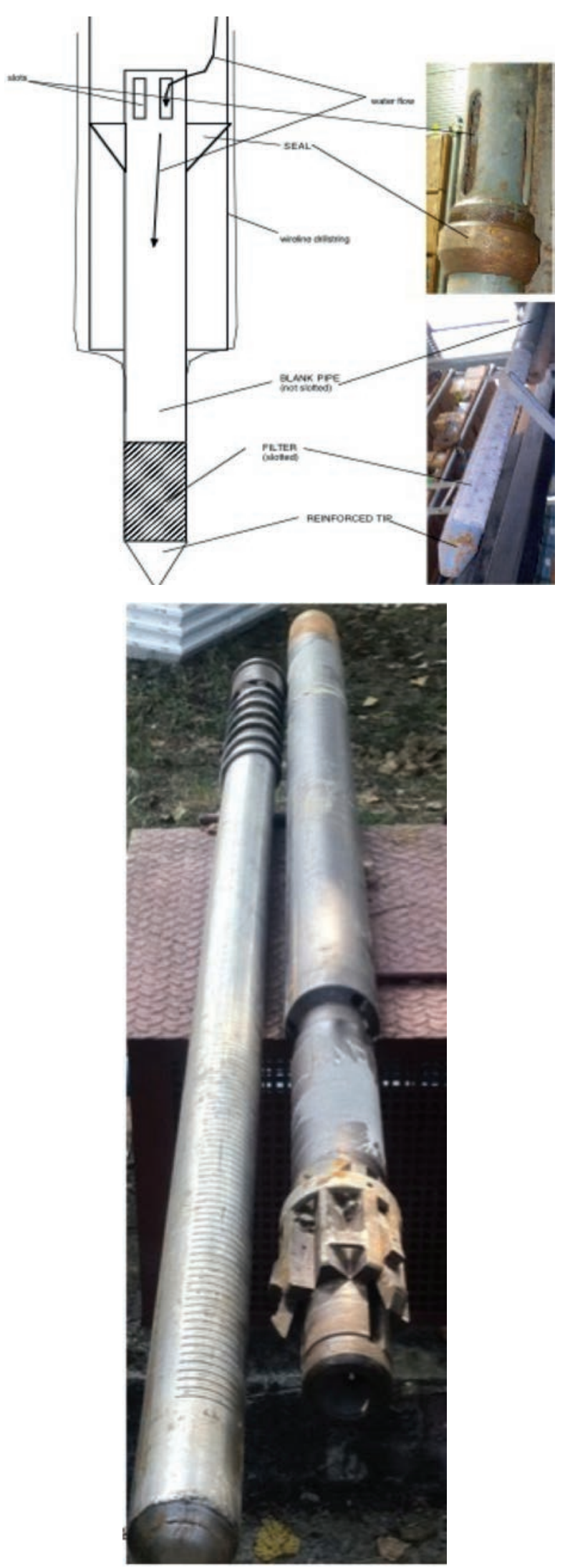

Fig. 7: Wireline permeameter Down-The-Hole (DTH) Water Well.

Fig. 7: Permeametro wireline (tipo pozzo d'acqua a fondo foro).

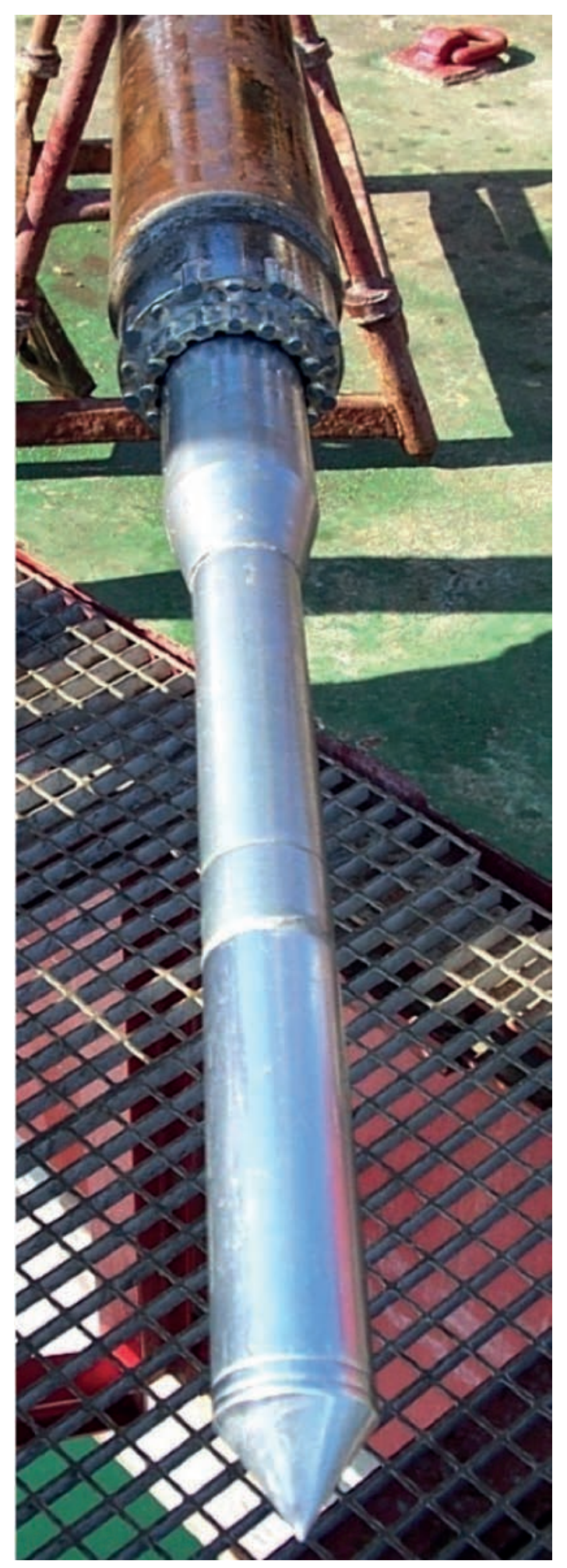

Fig. 8: Cone Penetration Test While Drilling (CPTWD®).

Fig. 8: Cone Penetration Test While Drilling (CPTWD®). 


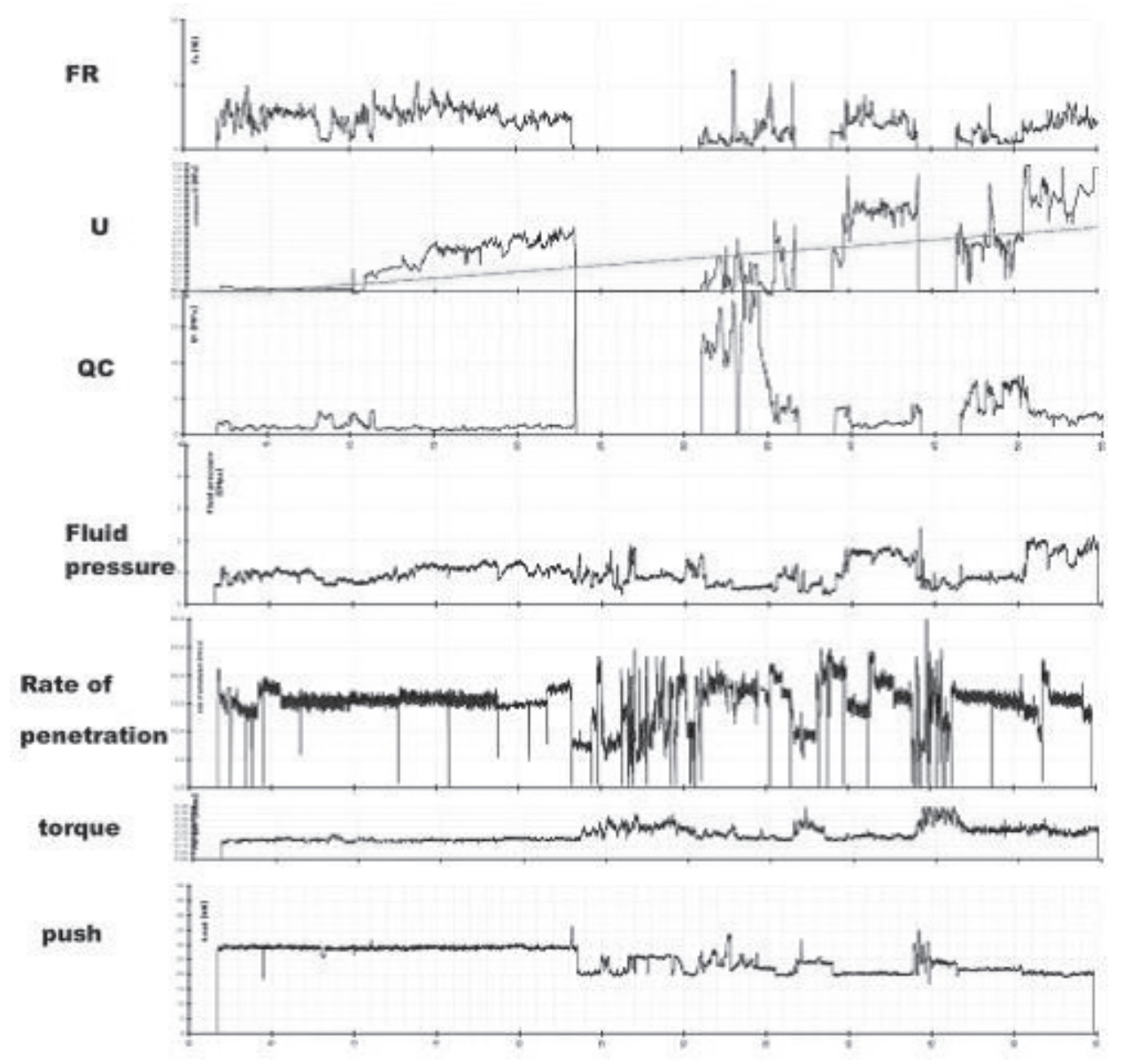

Fig. 9: Example of results of $C P T W D(C P T U$ coupled with $M W D$ ) test in clay and gravel.

Fig. 9: Esempio di risultati di una prova CPTWD (CPTU accoppiato a MWD) in argilla e ghiaia.

\section{Wireline Core-Barrels and Samplers}

All kinds of standard samplers driven by rods (thin wall: Shelby, Piston Shelby, Osterberg, rotative: Denison, Craps, Mazier, etc) have been adapted to wireline, allowing the withdrawal of undisturbed samples of almost all kind of soils (Sacchetto et al. 2012).

\section{Wireline special tools}

Theoretically any kind of test with any drilling and testing tool can be (or already has been) adapted to wireline, for instance (and not only): Marchetti Dilatometer (Fig. 10), Vane Test, SPT, Sand Sampler with freezing, Environmental Cones, Pressumeter, etc.

\section{Conclusion}

Designers/consultants do not always have simultaneously the knowhow, the experience and the ability to manage orders in the best way, also considering practical aspects such as the sometimes limited availability of funds and time. In the same way geognostic drilling contractors are not always armed with all types of equipment and sufficient expertise for all techniques of prospection (e.g. deep drilling as required for certain hydrogeological objectives), and knowhow concerning the use and sometimes ad hoc development of special instruments for in-situ testing in all possible contexts. The above provides some starting points for discussion on how to implement advanced "geotechnical" drilling and testing methods and equipment in HYDROGEOLOGY. At present "hydrogeological" and "geotechnical" drilling are considered separately, although the Consultant dealing with Hydrogeology (water well design and contaminant hydrogeology) would need reliable data for project design.

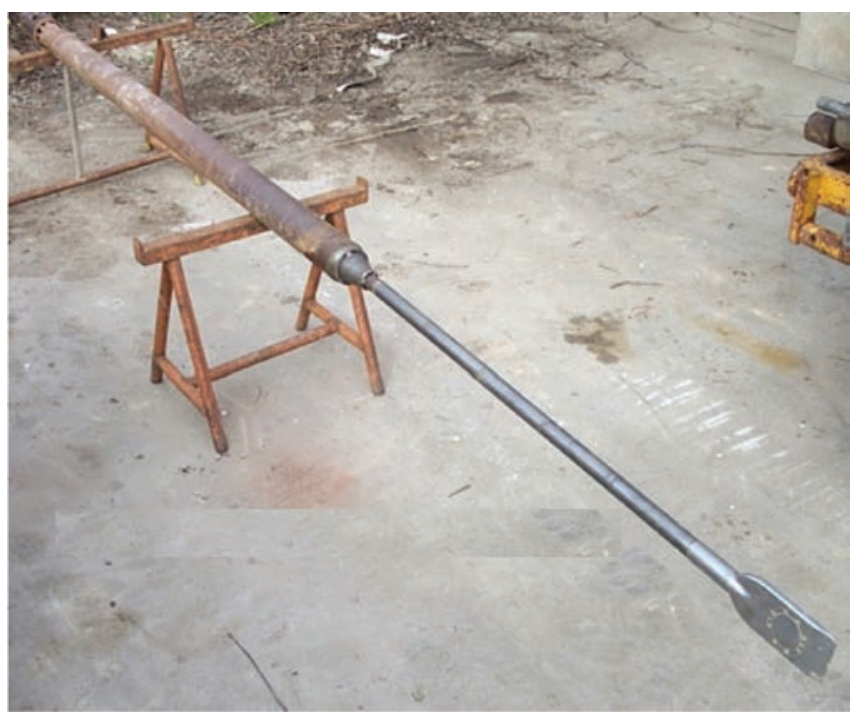

Fig. 10: Wireline Marchetti Dilatometer DMT.

Fig. 10: Dilatometro Marchetti Wireline DMT. 


\section{REFERENCES}

AGI Associazione Geotecnica Italiana (1977) Raccomandazioni sulla Programmazione ed Esecuzione delle Indagini Geotecniche "Recommendations on planning and execution of geotechnical investigations"

ASTM D5876 - 95 (Reapproved 2012) Standard Guide for Use of Direct Rotary Wireline Casing Advancement Drilling Methods for Geoenvironmental Exploration and Installation of Subsurface Water-Quality Monitoring Devices

Borgia G.C., Brighenti G., Mesini E. (1990) Consideration on subsoil exploration by means of istantaneous drilling parameters recording. 6th International I.A.E.G., pp. 289-295, Publisher Balkema, Rotterdam

Bru J., Ledoux J.L., Menard J., Washkowsky E. (1983) Les diagraphies et les essais de mecaniques des sols en place "Diagraphies and in situ testing of soil mechanics" Bulletin I.A.E.G., pp. 25-32, n. 26-27, Paris

Burgoyne Jr. A.T., Young Jr. F.S. (1974) A multiple regression approch to optimal drilling ad abnormal pressure detection. Society of Petroleum Engineers Journal, pp. 371-384

Cestari F. (2005) Prove geotecniche in sito "In situ geotechnical tests". 415 pp. Publisher: Geo-Graph Segrate
Hamelin J.P ., Levallois J., Pfister P . (1983) Enregistrement des parameters de forage: nouveaux developments "Recording of water well parameters: new developments". Bulletin I.A.E.G., pp. 83-88, n. 26-27, Paris

Lunne T. (2010) The CPT in offshore soil investigations - a historic perspective, from CPT'10 $2^{\text {nd }}$ International Symposium of Cone Penetration Tests. Publisher: CPT'10, Organizing Committee Volume 1, 2, 3

Mayne P. (2007) NCHRP - National Cooperative Highway Research Program: Cone Penetration Testing 117 pp. Publisher: Transportation Research Board USA

Melander K. (2001) Use of MWD (Ancona, Workshop on CPTWD, organized by prof. Colosimo)

Sacchetto M., Trevisan A. (2012) CPT executed in difficult conditions using CPTWD and future developments. From ISC 4 Proceedings, Pernambuco, Brazil (Geotechnical and Geophysical Site Characterization 4 ) Publisher: Taylor and Francis Group, London, UK Volume 1 and Volume 2

Sacchetto M., Trevisan A., Melander K., Elmgren K. (2004) - CPTWD (Cone Penetration Test While Drilling) a new method for deep geotechnical surveys - ISC2 Porto. Publisher: Millpress, Rotterdam, Volume 1 and Volume 2 